\title{
Produção de Forragem e Retorno Econômico da Pastagem de Aveia e Azevém sob Pastejo com Bezerras de Corte Submetidas a Níveis de Suplementação Energética 1
}

\author{
Adriana Frizzo을 Marta Gomes da Rocha ${ }^{3}$, João Restle ${ }^{4}$, Mário Ruschel Freitas ${ }^{5}$, \\ Georgia Biscaíno 6 , Alcides Pilau ${ }^{6}$
}

\begin{abstract}
RESUMO - O experimento avaliou a produção de forragem da aveia preta (Avena strigosa Schreb) mais azevém (Loliummultiflorum Lam.) sob pastejo com bezerras da raça Charolês e suas cruzas com Nelore, submetidas aos seguintes tratamentos: 0; 0,7 e 1,4\% do peso vivo (PV/dia) de suplementação com farelo de arroz integral e polpa cítrica, na proporção de 1:1. Foram avaliadas as taxas de acumulação diária de matéria seca (TA), composição botânica, perdas de forragem e retorno econômico do uso de diferentes níveis de suplementação. Os tratamentos suplementados apresentaram maior TA, embora o nível de 1,4\% do PV não tenha diferido dos tratamentos sem suplementação e suplementação de $0,7 \%$ do PV. As perdas de massa de forragem foram de 2,61; 1,91 e 1,41\% do PV, respectivamente. O custo total (C) foi de 289,97; 477,17 e 749,94 R \$/ha, sendo a renda bruta (RB) obtida de 551,46; 732,29 e 872,56 R \$/ha. A renda líquida foi de 261,49; 255,15 e 122,62 R \$/ha. As relações RB/C foram de 1,90; 1,54 e 1,16, para o tratamento não suplementado, $0,7 \%$ e $1,4 \%$ do PV/dia, respectivamente.
\end{abstract}

Palavras-chave: farelo de arroz, pastejo contínuo, perdas de forragem, polpa cítrica, renda bruta

\section{Production of Forage and Economic Return in an Oat plus Italian Ryegrass Pasture under Grazing with Beef Heifers Submitted to Levels of Energy Supplementation}

\begin{abstract}
It was evaluated the forage production from black oat (Avena strigosa Schreb) plus italian ryegrass (Lolium multiflorum Lam) mixture under grazing with beef heifers of Charolais breed and their crosses with Nellore submitted to following treatments: $0,0.7$, and $1.4 \%$ live weight/day of supplementation of rice bran plus citrus pulp (1:1). Daily dry matter accumulation rate (TA), botanical composition, forage losses and economic return of the different levels of supplementation were evaluated. The treatments with supplementation increased TA, however, the supplement level of 1,4\% did not differ from the $0 \%$ level. Forage mass losses represented $2.61,1.91$, and $1.41 \%$ of the live weight/day for $0,0.7$, and $1.4 \%$ supplementation levels, respectively. The total costs (C) were $289.49,477.17$, and $749.49 \mathrm{R} \$ /$ ha. The gross incomes (GI) were of 551.46, 723.29, and 872.56 R $\$ /$ ha. The net incomes were 261.49 , 255.15 , and $122.62 \mathrm{R} \$ /$ ha. The GI/C ratio were $1.90,1.54$, and 1.16 for the treatments $0,0.7$ and $1.4 \% \mathrm{LW} /$ day, respectively.
\end{abstract}

Key Words: rice bran, continuous grazing, forage losses, botanical composition, citric pulp, gross income

\section{Introdução}

A base da alimentação para a pecuária no Estado do Rio Grande do Sul é o campo nativo, que apresenta uma deficiência na produção de forragem no inverno, constituindo-se uma das principais causas para o desequilíbrio no desempenho animal. A intensificação crescente na produção de bovinos de corte tem levado o produtor a buscar nas pastagens cultivadas uma resposta mais imediata para obter maior produtividade.

No Rio Grande do Sul, as espécies mais utilizadas para pastagens de inverno são a aveia preta e o azevém. A aveia apresenta uma área de cultivo superior a do azevém, sendo a espécie preferida na integração lavoura-pecuária, por ter um ciclo de produção mais curto. $\mathrm{O}$ azevém é utilizado pela sua facilidade de ressemeadura natural, resistência a doenças, bom potencial de produção de sementes e versatilidade de uso em associações (Moraes, 1994). Resultados de pesquisa tem demonstrado o elevado potencial de produção de pastagens cultivadas de inverno como aveia e azevém (Restle et al., 1997; Lupatini et al., 1998).

${ }^{1}$ Parte da tese de Mestrado da primeira autora.

2 Zoot. Ms. Aluna do curso de Doutorado da UFRGS. E.mail: adrianafrizzo@yahoo.com.br

${ }^{3}$ Eng.-Agr. Dr ${ }^{\mathrm{a}}$. Prof ${ }^{\mathrm{a}}$. Adjunta do Departamento de Zootecnia - UFSM. R. Tuiuti 1554/201, CEP 97015662, Centro, Santa Maria, RS.

E.mail: tata@pro.via-rs.com.br

4 Eng.-Agr. PhD. Prof. Titular do Departamento de Zootecnia - UFSM. E.mail: jorestle@ccr.ufsm.br

5 Eng.-Agr. Aluna do curso de Pós-Graduação em Zootecnia, Bolsista CNPq, UFSM.

6 Zoot. Aluno do curso de Pós-Graduação em Zootecnia. Bolsista CAPES, UFSM. 
Na maioria das situações, a forragem não contém todos os nutrientes essenciais, na proporção adequada, de forma a atender integralmente as exigências dos animais em pastejo (Hogdson, 1990). Assim, nutrientes suplementares são necessários para se obter melhor desempenho animal.

Em sistemas de produção, a suplementaçãocom concentrado para categorias de animais que possuem maior exigência nutricional, através da utilização de subprodutos industriais como a polpa cítrica e o farelo de arroz, poderia servir para atingir os objetivos da pecuária, como também minimizar os efeitos das adversidades climáticas, assegurando um desenvolvimento adequado dos animais com o fornecimento de nutrientes escassos e podendo melhorar a relação receita bruta/custo.

A suplementação com concentrados energéticos pode ter distintos objetivos como aumentar a oferta de forragem, quando esta apresentar baixa disponibilidade, ou atender as exigências nutricionais para a obtenção de melhor desempenho (Vaz Martins, 1997). A primeira destas opções implica em ganhos de peso individuais moderados e elevados ganhos por área, enquanto a segunda implica em ganhos individuais máximos, devido ao aumento no consumo de energia.

$\mathrm{O}$ risco da dependência exclusiva de pastagens estabelecidas anualmente é maior para determinadas categorias animais como bezerras de corte para acasalamento com um ano de idade. Para esta categoria é indispensável um nível alimentar alto e contínuo, o qual poderia ser assegurado através do fornecimento de suplementação.

Considerando-se que os custos de implantação das pastagens são relativamente altos, é necessário que tanto o manejo como os recursos sejam utilizados da maneira mais eficiente e racional possível. Restle et al. (1993) mostraram que a mistura de aveia preta e azevém apresentou um bom retorno econômico quando submetida a diferentes níveis de adubação nitrogenada. Roso \& Restle (2000) avaliando misturas de aveia preta, triticale e centeio com azevém e utilizando a mesma categoria animal do presente trabalho verificaram que a pastagem composta pela mistura de aveia e azevém apresentou o menor custo, embora a maior receita líquida tenha sido obtida na mistura de triticale e azevém.

Existem poucos trabalhos com informações sobre a dinâmica da pastagem e a economicidade da utilização de suplementação em pastagens cultivadas de inverno. Neste sentido, este trabalho teve como objetivos avaliar a produtividade e a economicidade da pastagem de aveia e azevém sob pastejo contínuo com bezerras recebendo diferentes níveis de suplementação energética.

\section{Material e Métodos}

O experimento foi realizado no período de maio a novembro de 1999. O solo da área experimental é classificado como ARGISSOLO VERMELHO Distrófico Arênico (EMBRAPA, 1999) pertencente à unidade de mapeamento São Pedro. O clima da região é Cfa (subtropical úmido), conforme classificação de Köppen (Moreno, 1961).

A área utilizada foi de 8,5 ha com nove divisões, mais uma área contígua de 8,5 ha, totalizando 17 ha. A semeadura da pastagem foi realizada após aplicação de herbicida glifosato, na dosagem de três litros/ ha, no dia 01 de maio de 1999 com uma semeadoraadubadora de 13 linhas e espaçamento entre linhas de $0,17 \mathrm{~m}$. Foram utilizados $80 \mathrm{~kg} / \mathrm{ha}$ de aveia preta (Avena strigosa Schreb) e $30 \mathrm{~kg} / \mathrm{ha}$ de azevém (Lolium multiflorum Lam.), previamente misturados e com valor cultural corrigido para $100 \%$. A adubação empregada foi de $200 \mathrm{~kg} / \mathrm{ha}$ da fórmula 10-20-10 e $90 \mathrm{~kg} / \mathrm{ha}$ de nitrogênio em cobertura, na forma de uréia, distribuído em quatro aplicações: 03/06, 14/07, 29/08 e 05/10.

Os tratamentos consistiram em diferentes níveis de suplementação, sendo eles: 0; 0,7 e 1,4 \% do PV/ dia, utilizando $50 \%$ de farelo de arroz integral e $50 \%$ de polpa cítrica, que misturados foram fornecidos diariamente às 14:00 horas.

O método de pastejo foi o contínuo com lotação variável, empregando a técnica de "put and take" (Mott \& Lucas, 1952), adotando a disponibilidade de forragem de $1500 \mathrm{~kg} /$ ha de matéria seca (MS). O período de pastejo foi de 09/07 a 12/11 de 1999, sendo utilizadas 64 bezerras de corte da raça Charolês e suas cruzas com Nelore, com sete meses de idade e peso médio inicial de $192 \mathrm{~kg}$. Os grupos raciais foram balanceados dentro do grupo de animais testers, sendo que cada tratamento era constituído por um animal Charolês (Ch), um $1 / 2$ Ch $1 / 2$ Nelore $(\mathrm{N})$ e o outro $3 / 4$ Ch $1 / 4 \mathrm{~N}$.

A disponibilidade de forragem da pastagem foi avaliada através da técnica de dupla amostragem (Wilm, 1944). Esta avaliação foi realizada a cada 28 dias, onde em cada unidade experimental cinco amostras foram cortadas $\left(0,25 \mathrm{~m}^{2} /\right.$ amostra $)$ e 15 avaliadas 
visualmente. A forragem proveniente das amostras cortadas foi homogeneizada e, posteriormente, duas amostras compostas foram retiradas. Uma amostra foi utilizada para a estimativa da composição botânica da pastagem e a outra para a determinação do teor de MS, proteína bruta (PB), pelo método micro Kjedahl (AOAC, 1984) e digestibilidade in vitro da matéria seca e orgânica (DIVMS e DIVMO) usando a metodologia de Tilley \& Terry (1963). Na amostra para determinação da composição botânica, as frações folhas, colmo, material senescente e material morto foram separadas manualmente. Os componentes botânicos foram secados para estimativa do percentual de cada componente em base de MS. As amostras foram secas em estufa de ar forçado a $65^{\circ} \mathrm{C}$.

A estimativa da taxa de acumulação diária de MS foi feita a cada 28 dias, utilizando-se três gaiolas de exclusão ao pastejo por unidade experimental. Cada amostra era proveniente de uma área de $0,25 \mathrm{~m}^{2}$. A taxa de acúmulo de MS do período foi estimada por intermédio da equação descrita por Campbell (1966). A produção total de MS foi calculada pelo somatório das produções dos períodos (taxa de acúmulo diário $\mathrm{x}$ número de dias do período) mais a disponibilidade inicial de forragem.

A estimativa do percentual de produção de MS dos componentes botânicos das espécies foi obtida dividindo a produção dos componentes botânicos em cada período pela produção total de matéria seca do mesmo e multiplicado por 100 .

As perdas de forragem foram avaliadas a cada 28 dias. No período inicial de pastejo foram demarcados 20 pontos amostrais dentro de cada unidade experimental. Em cada ponto amostral foi colocado um quadrado com área de $0,02 \mathrm{~m}^{2}$, no qual, a cada avaliação (16/07, 14/08, 17/09 e 16/10) era recolhida a forragem considerada não aproveitável pelos animais (material senescente, morto e danificado pelo pisoteio e pastejo). Após cada coleta, as amostras foram secadas em estufa a $65^{\circ} \mathrm{C}$ e pesadas.

Os cálculos de custos foram feitos em planilhas eletrônicas do programa EXCEL, versão 2000. Foram considerados fixos os custos de mecanização, dessecação, plantio, adubação de manutenção e nitrogenada. $\mathrm{O}$ custo obtido em função dos níveis de suplementação foi considerado variável, sendo este composto pelo suplemento e seu fornecimento, cochos, sal e vermífugos utilizados durante o período experimental. O custo total de cada tratamento foi composto pelos custos fixos mais os custos variáveis.
Para o cálculo da renda bruta foi considerado o preço médio do bezerro no mês de agosto de 2000. A receita líquida foi obtida pela diferença entre a renda bruta total, calculada através do valor da comercialização da carne, que é expressa em ganho de peso vivo/ha, e o custo total da pastagem de aveia e azevém com ou sem suplementação.

$\mathrm{O}$ delineamento experimental foi o inteiramente casualizado, com três repetições. Os dados coletados, com exceção dos dados da análise econômica, foram submetidos à análise de variância, através do General Linear Models Procedure (Proc GLM), teste de Tukey à $5 \%$ e análise de regressão, através do programa estatístico SAS (1990).

Na análise de variância, usou-se o modelo matemático abaixo:

$$
Y_{i j k}=m+T_{i}+P_{j}+T_{i} P_{j}+E_{i j k}
$$

em que: $\mathrm{Y}_{\mathrm{ijk}}=$ variável dependente; $\mathrm{m}=$ média das observações; $T_{i}=$ efeito do ${ }_{i}$ tratamento; $P_{j}=$ efeito do j período; $\mathrm{T}_{\mathrm{i}} \mathrm{P}_{\mathrm{j}}=$ efeito da interação entre $\mathrm{o}_{\mathrm{i}}$ tratamento e o ${ }_{j}$ período; e $E_{i j k}=$ efeito do erro aleatório associado a cada observação $\mathrm{k}$.

\section{Resultados e Discussão}

O valor médio da disponibilidade de forragem, correspondente ao período experimental, foi de $1597 \mathrm{~kg} / \mathrm{ha}$ de MS, sendo este valor próximo aos valores obtidos por vários autores na condução de experimentos de pastejo com espécies anuais de inverno (Soares, 1999; Pascoal et al., 2000; Roso \& Restle, 2000).

Na Tabela 1, encontram-se os valores em percentagem de MS, PB e DIVMO da forragem disponível na pastagem de aveia e azevém. Não houve interação $(\mathrm{P}>0,05)$ entre níveis de suplementação e períodos de utilização da pastagem para \% MS, \% PB e \%DIVMO.

Os valores médios de \%MS não diferiram $(\mathrm{P}>0,05)$ entre os tratamentos, sendo na média de $21,7 \%$. Observa-se que o teor de MS nos diferentes períodos apresentou um aumento linear com o avanço dos períodos de utilização da pastagem onde a regressão linear mostrou um aumento de 0,23 pontos percentuais na MS a cada dia de pastejo. Em pastagens constituídas por duas ou mais espécies este comportamento geralmente é cúbico (Soares \& Restle, 1999), no qual o teor de MS vai aumentando até que o azevém começa a participar significativamente da pastagem, quando então, o teor de MS diminui, devido ao maior número de folhas presentes. No presente trabalho, o azevém 
Tabela 1- Porcentagem de matéria seca (MS), proteína bruta (PB) e digestibilidade in vitro da matéria orgânica (DIVMO) da forragem disponível em pastagem de aveia e azevém sob pastejo contínuo de bezerras de corte submetidas a diferentes níveis de suplementação energética

Table 1 - Percentage of dry matter (DM), crude protein (CP) and "in vitro" organic matter digestibility (IVOMD) of available forage in pasture of oat plus Italian ryegrass under continuous grazing with beef heifers with different energetic supplementation levels

\begin{tabular}{lcccccc}
\hline $\begin{array}{l}\text { Tratamento } \\
\text { Treatment }\end{array}$ & \multicolumn{5}{c}{$\begin{array}{c}\text { Período } \\
\text { Period }\end{array}$} & $\begin{array}{c}\text { Média } \\
\text { Average }\end{array}$ \\
\cline { 2 - 5 } & $09 / 07-05 / 08$ & $05 / 08-03 / 09$ & $03 / 09-01 / 10$ & $01 / 10-29 / 10$ & $29 / 10-12 / 11$ & \\
\hline MS (\%) & 14,50 & 17,50 & 20,10 & 20,00 & 36,20 & 21,7 \\
$D M(\%)$ & 9,32 & 10,61 & 12,38 & 8,21 & 9,90 & 9,75 \\
PB (\%) & 75,09 & 75,74 & 61,73 & 56,42 & 54,15 & 64,87 \\
CP (\%) & & & & & & \\
DIVMO (\%) & & & & &
\end{tabular}

$\mathrm{MS}=4,70+0,23 \mathrm{P}^{*}\left(\mathrm{P}<0,034 ; \mathrm{R}^{2}=0,5123\right)$

$\% \mathrm{~PB}=12,23-0,029 \mathrm{P}\left(\mathrm{P}<0,007 ; \mathrm{R}^{2}=0,2793\right)$

$\%$ DIVMO $=85,15-0,24 \mathrm{P}\left(\mathrm{P}<0,033 ; \mathrm{R}^{2}=0,5992\right)$

${ }^{*} \mathrm{P}=$ dia de pastejo ( ${ }^{*} P=$ days of grazing).

teve contribuição significativa na composição botânica desde o primeiro período e, desta maneira, a porcentagem de MS da mistura seguiu a tendência de pastagens formadas por uma só espécie.

As médias de porcentagem de PB não diferiram $(\mathrm{P}>0,05)$ entre os diferentes níveis de suplementação, sendo o valor médio encontrado de 9,75\%. Vários autores (Quadros \& Maraschin, 1987; Roso et al.,1999; Soares, 1999; Restle et al., 2000; Roso \& Restle, 2000) encontraram valores de proteína bruta, em pastagens de inverno, bem superiores aos obtidos no presente experimento. Prováveis explicações para os baixos teores de PB encontrados na forragem disponível estão relacionadas com o método de estabelecimento da pastagem e forma de amostragem. A pastagem foi estabelecida por plantio direto, e as amostras foram retiradas com cortes rente ao solo, e continham material morto, proveniente da dessecação. Além disso, existia também elevado percentual de colmos de aveia na massa de forragem, durante o ciclo vegetativo destas forrageiras.

Muehlmann et al. (1997) avaliando o efeito exclusivo de pastagens no desenvolvimento de bezerras de corte e realizando a separação das frações das pastagens observaram que a fração verde que era composta por folhas e colmos tenros, apresentaram PB e DIVMO superiores aos aqui registrados. Os autores observaram que o desempenho dos animais foi maior nas pastagens com maior percentagem de folhas verdes.

A percentagem de $\mathrm{PB}$ apresentou uma tendência de decréscimo com o avanço da idade vegetativa das forrageiras onde a regressão linear mostrou uma diminuição de 0,02 pontos percentuais na $\mathrm{PB}$ a cada dia de pastejo. Este comportamento para porcentagem de PB na pastagem foi semelhante ao observado por Soares (1999).

As médias da porcentagem de DIVMO não diferiram $(\mathrm{P}>0,05)$ entre os níveis de suplementação, sendo o valor médio encontrado de $64,87 \%$. Soares (1999) trabalhando com a mesma categoria animal do presente trabalho e com diferentes níveis de $\mathrm{N}$ em pastagem de gramíneas de inverno, observou 65,88\% de DIVMO. Segundo Blaser et al. (1982), para ganhos na faixa de 0,750 a $1,1 \mathrm{~kg} / \mathrm{an} / \mathrm{dia}$, para a categoria de novilhos, é necessário que a forragem apresente digestibilidade de 67 a $74 \%$, respectivamente.

O teor de DIVMO apresentou decréscimo linear com o avanço da idade vegetativa das forrageiras, com a equação de regressão linear mostrando um decréscimo de 0,24 pontos percentuais na DIVMO a cada dia de pastejo. Segundo Blaser (1990) a redução no valor nutritivo da forragem com o avanço do ciclo das plantas deve-se ao aumento de carboidratos estruturais e lignina nos tecidos de sustentação da planta, bem como redução na relação folha/caule e aumento na porcentagem de material morto, que apresentam baixa digestibilidade. Conforme Preston \& Leng (1987) quando a digestibilidade da forragem é baixa, a distensão ruminal pode controlar o consumo. Assim, o tipo de suplemento a ser usado é dependente dos fatores que limitam o consumo de forragem pelos animais.

Os dados referentes à taxa de acumulação diária de MS encontram-se na Tabela 2. Não houve interação 
Tabela 2 - Taxa de acumulação de MS (kg/ha/dia de MS) e produção total de MS (PMS, kg/ha) em pastagem de aveia mais azevém sob pastejo contínuo com bezerras de corte recebendo diferentes níveis de suplementação energética

Table 2 - Accumulation rate ( $\mathrm{kg} D M / \mathrm{ha} /$ day) and total production of $D M(D M P, \mathrm{~kg} / \mathrm{ha}$ ) in pasture of oat plus Italian ryegrass under continuous grazing with beef heifers receiving different energetic supplementation levels

\begin{tabular}{|c|c|c|c|c|c|c|c|}
\hline \multirow[t]{2}{*}{$\begin{array}{l}\text { Tratamento } \\
\text { Treatment }\end{array}$} & \multicolumn{5}{|c|}{$\begin{array}{l}\text { Períodos } \\
\text { Periods }\end{array}$} & \multirow[t]{2}{*}{$\begin{array}{l}\text { Média } \\
\text { Average }\end{array}$} & \multirow[t]{2}{*}{$\begin{array}{l}\text { PMS } \\
D M P\end{array}$} \\
\hline & $22 / 06-19 / 07$ & $20 / 07-16 / 08$ & $17 / 08-13 / 09$ & $14 / 09-11 / 10$ & $12 / 10-09 / 11$ & & \\
\hline $\begin{array}{l}\text { Sem suplementação } \\
\text { No supplement }\end{array}$ & 22,88 & 56,79 & 45,47 & 49,89 & 53,81 & $45,76^{b}$ & $7238^{b}$ \\
\hline $\begin{array}{l}0,7 \% \mathrm{PV} \\
0.7 \% \mathrm{LW}\end{array}$ & 32,14 & 58,44 & 56,23 & 57,13 & 71,56 & $55,10^{\mathrm{a}}$ & $8868^{\mathrm{a}}$ \\
\hline $\begin{array}{l}1,4 \% \mathrm{PV} \\
1.4 \% L W\end{array}$ & 36,94 & 68,09 & 43,54 & 37,48 & 64,39 & $50,08^{\mathrm{ab}}$ & $7956^{\mathrm{ab}}$ \\
\hline Média & 30,65 & 61,10 & 48,41 & 48,16 & 63,25 & 50,31 & 8021 \\
\hline
\end{tabular}

Average

Médias seguidas de letras diferentes, na mesma coluna, diferem entre si pelo teste Tukey $(\mathrm{P}<0,05)$

Means followed by different letters in the same column differ $(P<.05)$ by Tukey test.

$(\mathrm{P}>0,05)$ entre tratamento e período de avaliação para a variável taxa de acumulação de matéria seca. Houve maior taxa de acumulação diária de forragem no tratamento suplementado em relação ao não suplementado, embora onível de 1,4\% do PV/dia não tenha diferido $(\mathrm{P}>0,05)$ dos demais. Os valores encontrados foram 45,76; 55,10 e 50,08 kg/ha/dia de MS para os níveis de $0 ; 0,7$ e 1,4\% do PV/dia, respectivamente. Como as condições de fertilidade, clima e as espécies foram semelhantes nos três tratamentos, a maior taxa de acumulação de forragem observada nos casos de suplementação mostra que os animais se comportaram diferentemente nas pastagens segundo os diferentes níveis de suplementação. Os dados coletados não foram suficientes para explicar esta interação, não sendo possível afirmar como este processo ocorreu. Segundo Jacques (1980), a quantidade de tecido fotossintético que permanece, após o corte, implicará em maior ou menor interceptação da energia luminosa no momento que as plantas iniciam novo crescimento, resultando em diferenças na quantidade de matéria seca acumulada.

A média da taxa de acúmulo da MS neste experimento é semelhante à obtida por Roso et al. (1999) e Roso \& Restle (2000) para misturas de gramíneas anuais de inverno e inferiores aos resultados obtidos por Lesama (1997), que trabalhou com pastagens de gramíneas e leguminosas com nitrogênio e aos de Lupatini et al. (1998) e Restle et al. (1998) que avaliaram pastagens de aveia preta e azevém.

As taxas de acumulação de MS foram inferiores no início da utilização da pastagem em relação aos demais períodos, sendo que este comportamento é resultante do efeito da temperatura e do menor comprimento do dia. De acordo com Carambula (1996), o comprimento do fotoperíodo e intensidade de luz, temperaturas e níveis de umidade e nutrientes afetam de forma notável os rendimentos de MS. À medida que diminuem a luz e a temperatura no outonoinverno, o crescimento é reduzido até chegar a primavera, quando ocorre uma retomada no crescimento.

A maior taxa de acumulação de MS foi observada no período de outubro à novembro. Isto se deve ao fato de que a pastagem estando no final do seu ciclo vegetativo, apresenta maior porcentagem de MS e material morto e senescente $(44,58 \%)$ que contribuiu para o aumento da MS. Outros autores obtiveram outros meses com maior taxa de acúmulo para pastagens de inverno: setembro e outubro (Lupatini et al., 1998), junho e julho (Roso et al., 1999) e agosto a setembro (Soares, 1999).

A produção total de forragem durante o período de utilização encontra-se na Tabela 2. As médias da variável produção total de forragem diferiram $(\mathrm{P}>0,05)$ entre os tratamentos. Os valores de produção total de forragem seguem o mesmo comportamento da taxa de acumulação por serem o somatório do produto desta pelo número de dias de cada período. Os valores encontrados para produção total de forragem foram $7238 ; 8868$ e $7956 \mathrm{~kg}$ /ha de MS para os níveis de $0 ; 0,7$ e $1,4 \%$ do PV/dia, respectivamente.

A produção obtida não traduz o potencial de espécies hibernais, pois valores próximos a $10000 \mathrm{~kg} /$ ha de MS foram obtidos por vários autores (Roso et 
al., 1998a; Roso \& Restle, 2000 e Roso et al., 1999). No entanto, produção total média mais baixa de forragem, $4220 \mathrm{~kg} / \mathrm{ha}$ MS, foi obtida por Canto et al. (1997).

Na Tabela 3, encontra-se o percentual dos componentes da massa de forragem por avaliação e suas respectivas médias. Não houve interação $(\mathrm{P}>0,05)$ para esta variável entre tratamento e período. Não foi observada diferença $(\mathrm{P}>0,05)$ para componentes botânicos entre os diferentes níveis de suplementação.

Em relação às médias dos componentes botânicos no período experimental, observa-se que a maior participação inicial foi a do componente folha de aveia, com média de $43,86 \%$ da forragem disponível

Tabela 3 - Percentual dos componentes da forragem disponível em pastagem de aveia mais azevém sob pastejo contínuo com bezerras recebendo diferentes níveis de suplementação energética

Table 3 - Percentage of forage mass components of avaluable forage in pasture of oat plus Italian ryegrass under continuous grazing with beef heifers receiving different energetic supplementation levels

\begin{tabular}{|c|c|c|c|c|c|c|c|}
\hline \multirow[t]{2}{*}{$\begin{array}{l}\text { Tratamento } \\
\text { Treatment }\end{array}$} & \multirow[t]{2}{*}{$\begin{array}{l}\text { Componentes } \\
\text { Components }\end{array}$} & \multicolumn{5}{|c|}{$\begin{array}{l}\text { Avaliações } \\
\text { Evaluations }\end{array}$} & \multirow[t]{2}{*}{$\begin{array}{l}\text { Média } \\
\text { Average }\end{array}$} \\
\hline & & $08 / 07$ & $05 / 08$ & $01 / 09$ & $28 / 09$ & $28 / 10$ & \\
\hline \multirow[t]{7}{*}{$\begin{array}{l}\text { Sem suplemento } \\
\text { No supplement }\end{array}$} & $\begin{array}{l}\text { Folha aveia } \\
\text { Oat leaf }\end{array}$ & 35,47 & 4,00 & 0,82 & 1,03 & 0,00 & 8,26 \\
\hline & $\begin{array}{l}\text { Colmo aveia } \\
\text { Oat stem }\end{array}$ & 18,07 & 37,17 & 30,46 & 18,67 & 0,00 & 20,87 \\
\hline & $\begin{array}{l}\text { Material senescente aveia } \\
\text { Oat senescent material }\end{array}$ & 9,23 & 10,03 & 4,90 & 2,90 & 0,00 & 5,41 \\
\hline & $\begin{array}{l}\text { Folha azevém } \\
\text { Italian ryegrass leaf }\end{array}$ & 23,19 & 33,66 & 26,72 & 14,58 & 17,46 & 23,12 \\
\hline & $\begin{array}{l}\text { Colmo azevém } \\
\text { Italian ryegrass stem }\end{array}$ & 0,00 & 4,18 & 12,89 & 29,62 & 34,94 & 16,33 \\
\hline & $\begin{array}{l}\text { Material senescente azevém } \\
\text { Ryegrass senescent material }\end{array}$ & 0,00 & 1,27 & 1,39 & 10,49 & 4,31 & 3,49 \\
\hline & $\begin{array}{l}\text { Material morto } \\
\text { Dead material }\end{array}$ & 14,04 & 9,67 & 22,79 & 22,70 & 43,28 & 22,49 \\
\hline \multirow[t]{7}{*}{$\begin{array}{l}\mathrm{O}, 7 \% \mathrm{PV} \\
0.7 \mathrm{LW}\end{array}$} & $\begin{array}{l}\text { Folha aveia } \\
\text { Oat leaf }\end{array}$ & 46,13 & 7,16 & 4,14 & 0,00 & 0,00 & 11,48 \\
\hline & $\begin{array}{l}\text { Colmo aveia } \\
\text { Oat stem }\end{array}$ & 28,19 & 32,82 & 16,94 & 6,36 & 0,00 & 16,86 \\
\hline & $\begin{array}{l}\text { Material senescente aveia } \\
\text { Oat senescent material }\end{array}$ & 8,45 & 15,81 & 4,52 & 5,25 & 0,00 & 6,80 \\
\hline & $\begin{array}{l}\text { Folha azevém } \\
\text { Italian ryegrass leaf }\end{array}$ & 19,06 & 27,56 & 19,04 & 25,22 & 20,86 & 22,35 \\
\hline & $\begin{array}{l}\text { Colmo azevém } \\
\text { Italian ryegrass stem }\end{array}$ & 0,00 & 4,02 & 12,14 & 39,13 & 37,68 & 18,59 \\
\hline & $\begin{array}{l}\text { Material senescente azevém } \\
\text { Ryegrass senescent material } \\
\text { Material morto }\end{array}$ & 0,00 & 2,50 & 14,10 & 11,56 & 4,85 & 6,60 \\
\hline & Dead material & 1,59 & 13,42 & 29,10 & 12,46 & 36,59 & 18,63 \\
\hline \multirow{7}{*}{$\begin{array}{l}1,4 \% \mathrm{PV} \\
1.4 \mathrm{LW}\end{array}$} & Folha aveia & 49,98 & 7,91 & 0,69 & 0,00 & 0,00 & 11,72 \\
\hline & $\begin{array}{l}\text { Oat leaf } \\
\text { Colmo aveia } \\
\text { Oat stem }\end{array}$ & 29,50 & 29,63 & 29,06 & 11,53 & 0,00 & 19,94 \\
\hline & $\begin{array}{l}\text { Material senescente aveia } \\
\text { Oat senescent material }\end{array}$ & 5,01 & 19,25 & 2,67 & 2,46 & 0,00 & 5,87 \\
\hline & $\begin{array}{l}\text { Folha azevém } \\
\text { Italian ryegrass leaf }\end{array}$ & 11,41 & 24,19 & 21,91 & 27,84 & 19,29 & 20,93 \\
\hline & $\begin{array}{l}\text { Colmo azevém } \\
\text { Italian ryegrass stem }\end{array}$ & 0,00 & 3,90 & 6,69 & 22,59 & 35,96 & 13,83 \\
\hline & $\begin{array}{l}\text { Material senescente azevém } \\
\text { Ryegrass senescent material }\end{array}$ & 0,00 & 2,07 & 8,32 & 17,34 & 5,98 & 6,74 \\
\hline & $\begin{array}{l}\text { Material morto } \\
\text { Dead material }\end{array}$ & 0,65 & 9,87 & 30,63 & 18,22 & 38,75 & 19,62 \\
\hline
\end{tabular}

$\mathrm{P}>0,05$. 
nos três tratamentos. O maior percentual deste componente foi encontrado no tratamento com $1,4 \%$ do $\mathrm{PV} /$ dia decrescendo à medida que foram reduzidos os níveis de suplementação. A percentagem de folhas de azevém foi menor quando houve suplementação. Observa-se que quanto maior o nível de suplementação menor foi a percentagem do componente folha de azevém na pastagem. Este fato mostra a seletividade realizada pelos animais quando estes receberam suplemento energético na dieta.

A participação do componente folha de aveia só foi expressiva durante o primeiro período, sendo que após o segundo período (05/08 a 01/09) houve um decréscimo significativo para este componente em todos os tratamentos. Estes resultados evidenciam a precocidade da aveia e a sua contribuição na produção inicial de forragem quando associada com o azevém. Restle et al. (1998) e Roso \& Restle (2000) também obtiveram os maiores percentuais de aveia durante o primeiro período de utilização das pastagens, sendo estes de 54,13 e 83,30\%, respectivamente.

Foi observado que a participação do componente folha de azevém foi relativamente constante durante todo o período experimental. Resultados diferentes foram obtidos por Soares (1999) que registrou a participação do azevém na forragem disponível da pastagem desde o início do pastejo, existindo um aumento na sua participação até atingir o mês de outubro, quando a sua participação foi máxima $(72,43 \%)$. Roso et al. (1999) observaram uma pequena contribuição do azevém no período inicial, chegando a valores máximos em setembro e outubro com 70,83 e $68,76 \%$, na média dos tratamentos, respectivamente.

O maior percentual de material morto foi observado, numericamente $(\mathrm{P}>0,05)$, quando não houve suplementação dos animais $(22,49 \%)$ e o menor no tratamento com $0,7 \%$ do PV/dia $(18,63)$, enquanto que a suplementação de 1,4\% do PV/dia apresentou um percentual intermediário $(19,62)$. A menor carga animal verificada no tratamento sem suplementação dos animais, provavelmente determinou menor freqüência na desfolhação das espécies forrageiras, mantendo uma maior quantidade de material morto no perfil da pastagem, o que não ocorreu com os tratamentos com suplementação dos animais onde a remoção da forragem era mais rápida, diminuindo as perdas por senescência. De acordo com Blaser (1990) quanto mais intensos e menos freqüentes os pastejos, maior é a produção de matéria seca, sendo que este fato ocorre até o limite em que o aumento por envelhecimento e decomposição ultrapassa o crescimento. Roso \& Restle (2000) encontraram, com preparo convencional do solo, valores de material morto, na média dos tratamentos, de 24,7; 22,5 e $30,7 \%$ para as misturas de aveia, triticale e centeio com azevém, respectivamente.

As perdas médias de forragem em $\mathrm{kg} / \mathrm{ha} / \mathrm{dia}$ de MS e a porcentagem de PV podem ser observadas na Tabela 4. Não houve interação $(\mathrm{P}>0,05)$ para nível de suplementação e período de utilização da pastagem para a variável perda de forragem. Não foi encontrada diferença $(\mathrm{P}>0,05)$ para a variável perda de forragem nos diferentes níveis de suplementação.

Tabela 4 - Perdas de forragem, expressas em percentagem de peso vivo, em pastagem de aveia mais azevém, sob pastejo contínuo com bezerras de corte recebendo diferentes níveis de suplementação energética

Table 4 - Forage losses expressed in percentage of live weight, in pasture of oat plus Italian ryegrass under continuous grazing with beef heifers receiving different energetic supplementation levels

\begin{tabular}{|c|c|c|c|c|c|}
\hline \multirow[t]{2}{*}{$\begin{array}{l}\text { Tratamentos } \\
\text { Treatments }\end{array}$} & \multicolumn{4}{|c|}{$\begin{array}{l}\text { Períodos } \\
\text { Periods }\end{array}$} & \multirow[t]{2}{*}{$\begin{array}{l}\text { Médial } \\
\text { Average }^{1}\end{array}$} \\
\hline & $16 / 07-13 / 08$ & $14 / 08-16 / 09$ & $17 / 09-15 / 10$ & $16 / 10-10 / 11$ & \\
\hline $\begin{array}{l}\text { Sem suplementação } \\
\text { No supplement }\end{array}$ & 2,19 & 4,85 & 2,28 & 1,13 & 2,61 \\
\hline $\begin{array}{l}0,7 \% \mathrm{PV} \\
0.7 \% L W\end{array}$ & 2,46 & 2,45 & 1,93 & 0,82 & 1,91 \\
\hline $\begin{array}{l}1,4 \% \mathrm{PV} \\
1.4 \% \mathrm{LW}\end{array}$ & 1,48 & 1,71 & 2,12 & 0,36 & 1,41 \\
\hline $\begin{array}{l}\text { Média } \\
\text { Average }\end{array}$ & 2,03 & 3,00 & 2,11 & 0,77 & \\
\hline
\end{tabular}

1 PERDAS $=\mathrm{P}>0,05$ (Forage losses $=P>$.05).

2 PERDAS $=2,39+0,77 \mathrm{P}-0,0061 \mathrm{P}^{2}\left(\mathrm{P}<0,0029 ; \mathrm{R}^{2}=0,2847\right)$.

2 Forage losses $=2,39+.77 P-.0061 P^{2} \quad\left(P<.0029 ; P^{2}=.2847\right)$. 
O conhecimento da quantidade de forragem que é perdida para posteriormente ser reciclada no solo, é importante para que se possa conhecer o potencial de adaptação das espécies ao pastejo. Segundo Hillesheim (1988), a pastagem submetida a pastejo sofre perdas de forragem por pisoteio, por dificuldades no momento da apreensão e por senescência natural das plantas, sendo que a intensidade com que as perdas ocorrem é influenciada pelas condições climáticas, pelo estádio de desenvolvimento e pela arquitetura da planta, bem como pela carga animal e massa de forragem.

A carga animal média suportada nos tratamentos foi de $1065 ; 1349$ e $1761 \mathrm{~kg} / \mathrm{h}$ a de PV para os níveis de suplementação 0; 0,7 e 1,4\% do PV/dia, respectivamente. Quando não houve suplementação, ocorreu um percentual de perdas de 2,61, e nos tratamentos suplementados foram verificados percentuais menores, de 1,91 e 1,41 para os níveis 0,7 e 1,4\% do PV/ dia, respectivamente. Assim, pode-se observar que a percentagem de perdas diminuiu com o aumento do nível de suplemento dos animais e conseqüentemente com o aumento de taxa de lotação. Tendo em vista que altas taxas de lotação não alteraram o percentual de perdas, isto é uma demonstração da grande adaptação destas espécies ao pastejo.

A regressão que melhor explicou o comportamento da porcentagem de perdas foi a regressão quadrática, onde esta apresentou um aumento de $0,77 \%$ até o segundo período de avaliação e logo após decrescendo 0,006\% a cada dia de pastejo.

Valores de perdas inferiores aos deste trabalho foram encontrados por Roso \& Restle (1998a), que trabalhando com misturas anuais de inverno encontraram 0,$61 ; 0,66$ e $1,19 \%$ do $\mathrm{PV}$ de perdas na pastagem para os tratamentos utilizados. Soares (1999) trabalhando com pastagem de triticale e azevém submetida a níveis de nitrogênio encontrou valor médio de perdas de $0,84 \%$ do PV.

$\mathrm{Na}$ Tabela 5, estão quantificados os itens que contribuem para a composição dos custos da formação da pastagem de inverno. $O$ custo fixo $(\mathrm{R} \$ / \mathrm{ha})$ para os três tratamentos foi de 284,43 , existindo variação entre os custos variáveis. A quantidade de sal comum e vermífugos foi proporcional ao número de animais existentes em cada tratamento. A quantidade de cochos é diretamente dependente do número de animais a serem suplementados. A distribuição da suplementação é dependente do número de animais e do tempo gasto com implementos para levar o suplemento até o local da distribuição.
O custo total da utilização da pastagem foi de 289,$97 ; 477,17$ e $749,94 \mathrm{R} \$$ /ha para os tratamentos sem suplemento dos animais e suplementação com $0,7 \%$ do PV e $1,4 \%$ do PV, respectivamente. A maior participação no custo do tratamento com $1,4 \%$ do PV refere-se ao item suplemento em função do maior número de animais suportado pela pastagem.

Restle et al. (1999) avaliando a produção animal e retorno econômico em misturas de gramíneas anuais de estação fria, obtiveram (R $\$ /$ ha) 281,27 de custo fixo da pastagem, havendo uma pequena variação entre os custos pertinentes aos tratamentos. Restle et al. (2000) avaliando o retorno econômico em pastagem de aveia mais azevém adubada com fontes de nitrogênio em cobertura, obtiveram custo de 286,80 $\mathrm{R} \$ /$ ha no tratamento com uréia.

Os custos, a renda bruta, a receita líquida e a relação $\mathrm{RB} / \mathrm{C}$ são apresentados na Tabela 6. Os tratamentos com suplementação dos animais apresentaram maior renda bruta, de 732,29 e 872,56 R $\$ /$ ha para 0,7 e 1,4 \% do PV, respectivamente, em relação ao tratamento sem suplemento para os animais, que apresentou renda bruta de 551,46 R \$/ha.

As rendas brutas dos tratamentos com animais suplementados com 0,7 e 1,4\% do PV foram superiores em 32,8 e 58,2\%, respectivamente, em relação a renda do tratamento sem suplemento para os animais. Esta diferença é conseqüência do ganho de peso vivo/ha obtido nos diferentes tratamentos, que foi de 433,3; 559,3 e 696,4 kg de PV para os níveis de suplementação 0; 0,7 e 1,4\% do PV/dia, respectivamente. Restle et al. (1998b) avaliaram a eficiência e o desempenho de categorias de bovinos de corte em pastagem cultivada e constataram renda bruta ( $\mathrm{R} \$ / \mathrm{ha})$ de 448,50; 501,75 e 282,10 para bezerros, novilhos e vacas, respectivamente.

O tratamento que possibilitou maior renda líquida foi o sem suplementação para os animais, $\operatorname{com} 261,49$ $\mathrm{R}$ \$ha, seguido pelo tratamento com suplementação dos animais de $0,7 \%$ do PV com 255,15 R \$/ha. A menor renda líquida foi obtida na suplementação com $1,4 \%$ do PV, 122,62 R \$/ha. Com diferentes tratamentos em pastagens de inverno os valores de receita líquida (R/ha) oscilaram desde-102,34 R \$/ha (Restle et al., 1998) a 224,78 R $\$ /$ ha (Roso \& Restle, 2000).

A relação renda bruta/custos mostra o retorno financeiro direto, sendo que para cada $\mathrm{R} \$$ investido foi obtido um retorno de $\mathrm{R} \$ 1,90 ; \mathrm{R} \$ 1,54$ e $\mathrm{R}$ \$ 1,16 para o tratamento sem suplementação, suplementação com 0,7 e $1,4 \%$ do PV, respectivamente. Estes valores foram 
Tabela 5 - Custo da pastagem de gramíneas anuais de estação fria submetida ao pastejo por animais recebendo diferentes níveis suplementação energética

Table 5 - Cost of annual cool season pasture submitted to grazing with animals receiving different energetic supplementation levels

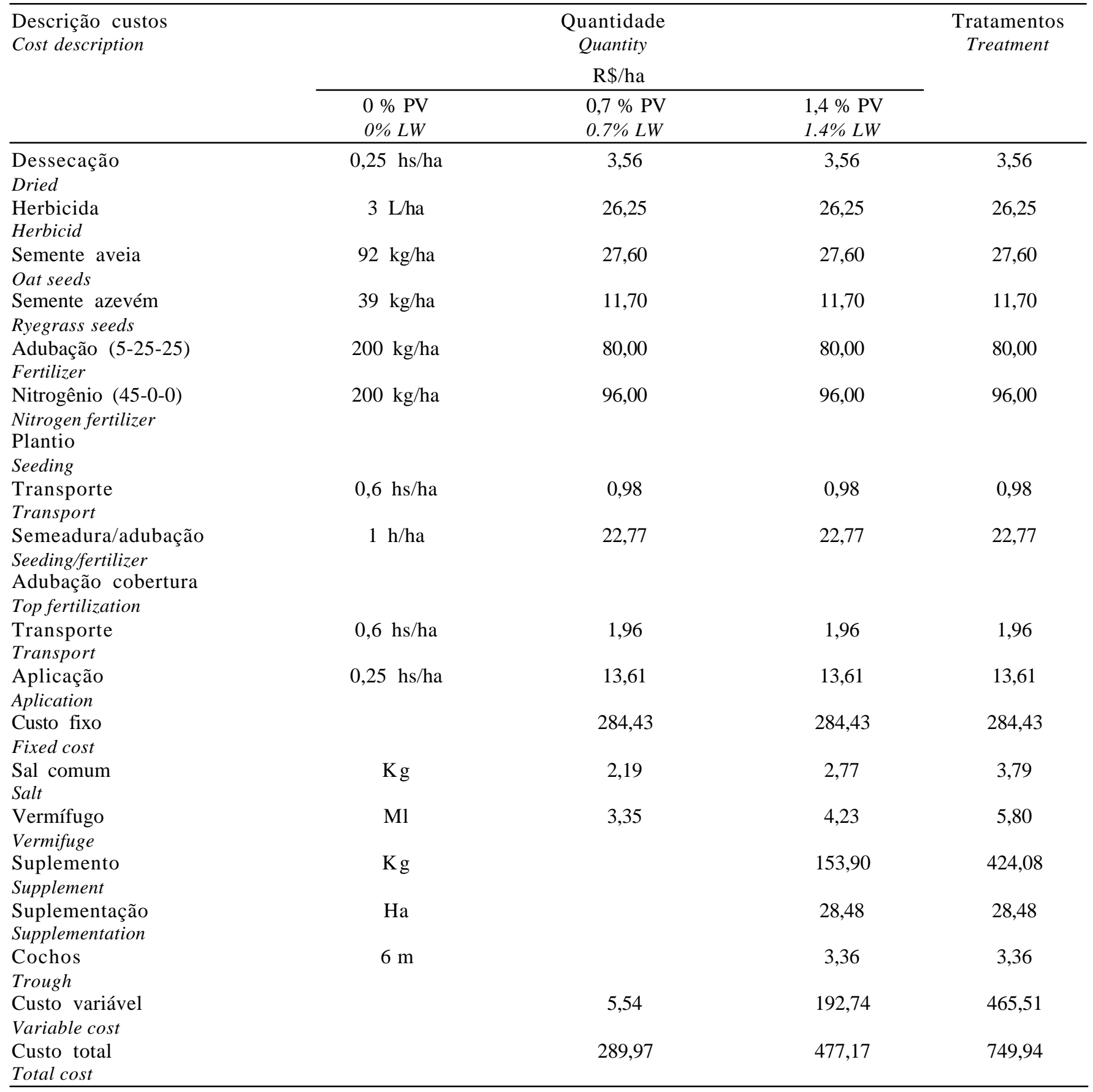

inferiores aos obtidos por Restle et al. (1993), que foram de 1,94 e 2,01 para as misturas de aveia e azevém com 150 ou $300 \mathrm{~kg} / \mathrm{ha}$ de $\mathrm{N}$ e superiores aos encontrados por Lesama (1997), que obteve uma relação RB/C de 1,11 na mistura de aveia preta mais $300 \mathrm{~kg} / \mathrm{ha}$ de $\mathrm{N}$.
A obtenção de maior receita líquida em pastagens está relacionado com o preço do suplemento e o preço de venda dos animais, ou seja, quantos quilos de suplemento são necessários para produzir um quilo de carne adicional. 
Tabela 6 - Custo total $(C)$, renda bruta $(R B)$, receita líquida e relação $R B / C$ em aveia mais azevém sob pastejo contínuo com bezerras de corte recebendo diferentes níveis de suplementação energética

Table 6 - Total cost (C), Gross income (GI), net income and RB/C ratio of oat plus Italian ryegrass under continuous grazing with beef heifers receiving different energetic supplementation levels

\begin{tabular}{|c|c|c|c|c|}
\hline $\begin{array}{l}\text { Tratamento } \\
\text { Treatment }\end{array}$ & $\begin{array}{c}\text { Custo total }(\mathrm{C}) \\
\text { Total cost }(C)\end{array}$ & $\begin{array}{r}\text { Renda bruta }(\mathrm{RB})^{1} \\
\text { Gross income }(G I)\end{array}$ & $\begin{array}{c}\text { Receita líquida } \\
\text { Net income }\end{array}$ & $\begin{array}{c}\text { Relação RB/C } \\
\text { RB/C Ratio } \\
\end{array}$ \\
\hline $\begin{array}{l}\text { Sem suplementação } \\
\text { No supplement }\end{array}$ & 289,97 & $\begin{array}{l}\mathrm{R} \$ / \mathrm{ha} \\
551,46\end{array}$ & 261,49 & 1,90 \\
\hline $\begin{array}{l}0,7 \% \mathrm{PV} \\
0.7 \% \mathrm{LW}\end{array}$ & 477,17 & 732,29 & 255,12 & 1,54 \\
\hline $\begin{array}{l}1,4 \% \mathrm{PV} \\
1.4 \% \mathrm{LW}\end{array}$ & 749,94 & 872,56 & 122,62 & 1,16 \\
\hline
\end{tabular}

${ }_{1}$ Preço por kg de peso vivo de bezerro ( $\left.\mathrm{R} \$ 1,30 / \mathrm{kg}\right)$.

${ }^{1}$ Price per $\mathrm{kg}$ of live weight for calves $(R \$ 1.30 / \mathrm{kg})$.

\section{Conclusões}

A suplementação energética de animais em pastagem de aveia e azevém não interfere nas porcentagens de MS, PB e DIVMO da forragem disponível.

Animais recebendo suplemento energético em pastagem de aveia e azevém selecionam lâminas foliares de azevém em detrimento de lâminas foliares de aveia.

Aveia e azevém mostram-se adaptados ao aumento de carga proporcionado por níveis altos de suplementação.

O aumento do nível de suplementação dos animais em pastagem de aveia e azevém embora tenha permitido acrécimo na carga animal/ha, resulta em menor renda líquida/ha.

\section{Literatura Citada}

\section{ASSOCIATION OF OFFICIAL ANALYTICAL CHEMISTS -} AOAC. Official methods of analysis. 14.ed. Washington, D.C.: 1984. 1141p.

BLASER, R.E. Integrated pasture and animal management. Tropical Grasslands, v.16, n.9, 1982.

BLASER, R.E. Manejo do complexo pastagem-animal para avaliação de plantas e desenvolvimento de sistemas de produção de forragens. In:Pastagens: fundamentos da exploração racional. 2.ed. Piracicaba: Fundação de Estudos Agrários "Luiz de Queiroz", 1990. p.157-205.

CAMPBELL, A.G. Grazed pastures parameters: I. Pasture dry matter production and availability in a stocking rate and grazing management experiment with dairy cows. Journal of Agricultural Science, v.67, n.2, p.211-216, 1966.

CANTO, M.W.; RESTLE, J.; QUADROS, F.L.E et al. Produção animal em pastagem de aveia (Avena strigosa Schreb) abubada com nitrogênio ou em mistura com ervilhaca (Vicia sativa L.). Revista Brasileira de Zootecnia, v.26, n.2, p.396-402, 1997.

CARAMBULA, M. Pasturas naturales mejoradas.
Montevideo: Ed. Hemisfério Sur:. 1996. 524p.

EMBRAPA. Centro Nacional de Pesquisa de Solos. Sistema brasileiro de classificação de solos. Brasília: EMBRAPA. 1999. $412 \mathrm{p}$.

HILLESHEIM, A. Manejo do gêneroPennisetum sob pastejo. In: SIMPÓSIO SOBRE MANEJO DA PASTAGEM, 9., 1998, Piracicaba. Anais... Piracicaba: Fundação de Estudos Agrários “Luiz de Queiroz", 1988.

HOGDSON, J. Grazing management. Science into practice. England: Lougman Group UK Ltda. Essex, 1990. p.203.

JACQUES, A.V.A. Fundamentos de manejo de plantas forrageirasárea foliar e reservas orgânicas. In: SEMINÁRIO SOBRE PASTAGENS "De que pastagens necessitamos", 1980. p.140-157.

LESAMA, M.F. Produção animal em gramíneas de estação fria com fertilização nitrogenada ou associada com leguminosa, com ou sem fertilização nitrogenada.Santa Maria: Universidade Federal de Santa Maria, 1997. 129p. Dissertação (Mestrado em Zootecnia) - Universidade Federal de Santa Maria, 1997.

LUPATINI, G.C.; RESTLE, J.; CERETTA, M. Avaliação da mistura de aveia preta e azevém sob pastejo submetida a níveis de nitrogênio. Pesquisa Agropecuária Brasileira, v.33, n.11, p.1939-1943, 1998.

MORAES, A. Culturas forrageiras de inverno. In: SIMPÓSIO BRASILEIRO DE FORRAGEIRAS E PASTAGENS, 1994, Campinas. Anais... Campinas: Colégio Brasileiro de Nutrição Animal, 1994. p.67-78.

MORENO, J.A. Clima do Rio Grande do Sul. Porto Alegre: Secretaria da Agricultura, 1961. 41p.

MOTT, G.O.; LUCAS, H.L. The design conduct and interpretation of grazing trials on cultivated and improved pastures. In: INTERNATIONAL GRASSLAND CONGRESS, 6., 1952, Pennsylvania. Proceedings... Pennsylvania: State College Press, 1952. p.1380-1395.

MUEHLMANN, L.D.; ROCHA, M.G.; RESTLE, J. Efeito do uso exclusivo de pastagem no desenvolvimento de bezerras de corte desmamadas precocemente. Revista Brasileira de Zootecnia, v.26, n.2, p.411-415, 1997.

PASCOAL, L.L.; RESTLE, J.; ALVES FILHO, D. et al. Desempenho de bezerros submetidos ao pastejo contínuo ou horário em pastagem cultivada de inverno, associado a suplementação energética. In: REUNIÃO ANUAL DA SOCIEDADE BRASILEIRA DE ZOOTECNIA, 37., 2000, Viçosa, MG. Anais... 
Viçosa: Sociedade Brasileira de Zootecnia/Gnosis, [2000].CDROOM. Nutrição de ruminantes.

PRESTON, T.R.; LENG, R.A.Matching ruminant production systems with available resources in the tropics and subtropics. Armidale: Penambul Books, 1987. 245p.

QUADROS, F.L.F.; MARASCHIN, G.E. Desempenho animal em misturas de espécies forrageiras de estação fria.Pesquisa Agropecuária Brasileira, v.22, n.5, p. 535-541, 1987.

RESTLE, J.; LUPATINI, G.C.; VALENTE, A.V. et al. Avaliação da mistura de aveia preta (Avena strigosa) e azevém (Lolium multiflorum) sob pastejo submetida a níveis de nitrogênio. IProdução animal. In: REUNIÃO ANUAL DA SOCIEDADE BRASILEIRA DE ZOOTECNIA, 30., 1993, Rio de Janeiro. Anais... Viçosa, MG: Sociedade Brasileira de Zootecnia, 1993. p.71.

RESTLE, J.; SOARES, A.B.; ROSO, G. Dinâmica de uma pastagem de aveia preta (Avena strigosa) e azevém (Lolium multiflorum) submetida a fontes de nitrogênio. In: REUNIÃO ANUAL DA SOCIEDADE BRASILEIRA DE ZOOTECNIA, 34., 1997, Juiz de Fora.Anais... Juiz de Fora: Sociedade Brasileira de Zootecnia,1997. p.179-181.

RESTLE, J.; LUPATINI, G.C.; ROSO, C. et al. Eficiência e desempenho de categorias de bovinos de corte em pastagem cultivada. Revista Brasileira de Zootecnia, v.27, n.2, p.397404, 1998.

RESTlE, J.; ROSO, C.; SOARES, A.B. Produção animal e retorno econômico em misturas de gramíneas anuais de estação fria. Revista Brasileira de Zootecnia, v.28, n.2, p.235-243, 1999.

RESTLE, J.; ROSO, C.; SOARES, A.B. Produtividade animal e retorno econômico em pastagem de aveia preta mais azevém adubada com fontes de nitrogênio em cobertura. Revista Brasileira de Zootecnia, v.29, n.2, p.357-364, 2000.

ROSO, C.; RESTLE, J. Perdas de forragem em pastagem com gramíneas anuais de estação fria sob pastejo contínuo. In: REUNIÃO ANUAL DA SOCIEDADE BRASILEIRA DE ZOOTECNIA, 35., 1998, Botucatu. Anais... Botucatu: Sociedade Brasileira de Zootecnia, 1998a. p.465-467.

ROSO, C.; RESTLE, J.; FILHO, D.C.A. et al. Dinâmica e produção de forragem em misturas de gramíneas anuais de estação fria sob pastejo contínuo. In: REUNIÃO ANUAL DA SOCIEDADE BRASILEIRA DE ZOOTECNIA, 35., 1998, Botucatu. Anais... Botucatu: Sociedade Brasileira de Zootecnia, 1998. p.459-461.
ROSO, C.; RESTLE, J. Análise econômica da utilização de pastagem com mistura de gramíneas anuais de estação fria. In: REUNIÃO ANUAL SOCIEDADE BRASILEIRA DE ZOOTECNIA 35., 1998, Botucatu. Anais... Botucatu: Sociedade Brasileira de Zootecnia, 1998b. p.471-473.

ROSO, C.; RESTLE, J.; SOARES, A.B. et al. Produção e qualidade de forragem da mistura de gramíneas anuais de estação fria sob pastejo contínuo. Revista Brasileira de Zootecnia, v.28, n.3, p.459-467, 1999.

ROSO, C.; RESTLE, J. Aveia preta, triticale e centeio em mistura com azevém. 2. Produtividade animal e retorno econômico. Revista Brasileira de Zootecnia, v.29, n.1, p.85-93, 2000.

SAS INSTITUTE Language reference. Version 6, Cary: 1990. $1042 p$

SOARES, A.B. Nível de adubação nitrogenada sobre a produtividade animal e da pastagem de triticale (xtriticosecale) e azevém (Lolium multiflorum). Santa Maria: Universidade Federal de Santa Maria, 1999. 189p. Dissertação (Mestrado em Zootecnia) - Universidade Federal de Santa Maria, 1999.

SOARES, A.B.; RESTLE, J. Produção animal em pastagem de triticale e azevém submetida a níveis de adubação nitrogenada. In: REUNIÃO ANUAL SOCIEDADE BRASILEIRA DE ZOOTECNIA, 36., 1999, Porto Alegre. Anais... Porto Alegre: Sociedade Brasileira de Zootecnia/Gnosis, [2000].CDROOM. Forragicultura.

TILLEY, J.M.A.; TERRY, R.A.A. Two stage technique for the "in vitro" digestion of forage crops. Journal of British Grassland Society, v.18, n.2, p.104-111, 1963.

VAZ MARTINS, D. Suplementación energética en condiciones de pastura limitante. Suplementacion estratégica para el engorde de ganado.INIA La Estanzuela. Uruguay. Série Técnica 83, p.17-22. 1997.

WILM, H.G.; COSTELLO, D.F.; KLIPPLE, G.E. Estimating forage yield by the double-sampling methods. Journal of American Society of Agronomy, v.36, p.194-203, 1944.

Recebido em: 17/05/01

Aceito em: 02/10/02 